\title{
Port Pricing Structures and Ship Efficiency
}

\author{
SIRI PETTERSEN STRANDENES* \\ Centre for International Economics and Shipping, Norwegian School of Economics and Business \\ Administration
}

\begin{abstract}
The paper discusses port pricing structures that enhance ship efficiency. Traditionally, ports use public infrastructure pricing, which does not take differences in waiting cost into considerations. We present two alternatives, a two part priority pricing scheme and port slot auctions, as alternative scheduling and pricing schemes that enhance ship efficiency.
\end{abstract}

\section{Introduction}

The success of containerisation of liner shipping stems from the remarkable increase in cargo handling efficiency and the parallel exploitation of economies of scale from vessel size. The resulting reduction in transport costs has fuelled world trade and seaborne transport. Costs are reduced both in deep- and short-sea shipping. Short-sea shipping faces strong competition from road transport, however and road transport has increased its share of the transport work.

Cost and efficiency in cargo handling depend not only on containerisation, but also on port efficiency in loading, unloading and forwarding the container to its final destination. Seaport efficiency is important in the maritime supply chain and for the competitiveness of short-sea shipping towards rail and road transport.

Both port and ship efficiency are influenced by the pricing structure and the scheduling procedure used by ports. By port efficiency we mean the degree of exploitation of the port capacity both quay and cargo handling capacity ${ }^{1}$. We measure ship efficiency as cargo carried per deadweight ton ${ }^{2}$ per period. Here we focus on changes in ship efficiency from any reduction in the turn around time in port and the time waiting for port access.

Seaports' pricing structures have been examples of traditional public infrastructure pricing. Hence, charges do not necessarily reflect the cost of providing the service.

* Centre for International Economics and Shipping, Norwegian School of Economics and Business Administration. Helleveien 30, N-5045 Bergen, Norway. Tel: +4755959254 , Fax +4755959350 Email: siri.strandenes@nhh.no I wish to thank participants in the executive seminar on "Critical issues facing the Port and Shipping Industry in the $21^{\text {st }}$ century" arranged by National University of Singapore $8^{\text {th }}$ March in Singapore for valuable comments.

${ }^{1}$ This is not the sole measure of port efficiency used in the literature. Cullinane (2002) gives an overview of criteria for port productivity and efficiency.

${ }^{2}$ Deadweight ton is the carrying capacity of a cargo vessel. 
Admission charges are related to the size of the vessel and the volume of cargo. Cargoes are charged separate fees for handling and storage. Water and equipment for the vessel's next journey are also charged separately. Such complexity makes it harder for ship operators to compare costs for alternative ports.

In seaports vessels have to be scheduled for loading and unloading. The standard procedure used by seaports is "first-come-first-serve", a scheduling procedure that is highly inefficient in economic terms, since it does not reflect relative waiting costs for the vessels. The rule disregards waiting cost and ship operator's willingness to pay higher port charges to increase the speed and reduce the carrying costs of capital for the cargo owner.

Shipping lines visiting a port on a regular basis may negotiate long term contracts with the port and thereby avoid the "first-come-first-serve" allocation rule. Investing in a terminal is seen as a long-term contract that secures port access. At the same time dedicated terminals may introduce inefficiencies in the allocation of the total port capacity. This is so, if the terminal is not fully utilised by its owners, and if the terminal owners do not let the excess capacity to others. Contracting out part of the port capacity by accepting long term contracts and dedicated terminals may also imply that short-term changes in plans are not accommodated. Thereby exploitation of the total port capacity may fall.

On the other hand ship efficiency increases when the ship operator can coordinate the terminal capacity and the routing of his vessel. The remaining port capacity is allocated by the "first-come-first-serve" rule. Hence, a large numbers of the vessels arriving at the port still are handled by the traditional allocation rule that disregards differences in waiting costs and thus reduces efficiency.

These pricing and scheduling problems are not unique for seaports. Airport charges reflect the weight of the aircraft and the number of passengers. One effect is that small aircraft that require more landing capacity are not charged accordingly. Small aircraft use more of the landing capacity since the minimum interval between aircraft movements is longer when smaller follow larger aircraft, than when only aircraft of similar size land at the airport. The reason is that smaller aircraft are sensitive to air turbulence caused by the larger aircraft. Following this, airports that handle both small and large aircraft can accommodate fewer take-offs and landings per hour than airports handling aircraft similar in size only.

In airports the system of "grandfather rights" reserves slots for the incumbent airline. Before deregulation landing slots were allocated in combination with the rights to operate specific routes. These slots were thus given to the monopoly airline operating in each route.

Both "first-come-first-serve" and "grandfather rights" are traditional allocation methods used by public infrastructure. Queuing or "first-come-first-serve" is also the most widely used allocation rule in such different applications as courts and hospitals. Thus, the challenge to public ports to find better scheduling procedures is shared by other infrastructure resources in the public domain as well.

The aim of this paper is to discuss and analyse different pricing schemes suggested for seaports with a focus on their effects on ship efficiency, and to compare them to the existing seaport pricing structure. For each of the suggested pricing alternatives we will focus on how pricing can be used to allocate port slots more efficiently than the traditional solution combining "first-come-first-serve" and long term contracts for dedicated terminals. The paper briefly comments on the existing pricing structures: traditional infrastructure charges and cost-based pricing. For a more thorough review of these pricing 
structures see Strandenes and Marlow (2000). We contrast the existing price structures to the suggested efficiency focusing pricing structures: (1) congestion pricing, (2) priority pricing, and (3) slot auctions. Congestion pricing has been implemented by some ports, whereas the suggested priority pricing and port slot auctions have not been tried. Port pricing as a means to increase port efficiency is discussed in for example Bennathan and Walters (1979) and Jansson (1984). The main contribution of this paper is to outline and discuss port pricing schemes that enhance ship efficiency. To discuss this we use a simple model of supply in seaborne transport.

\section{$2 \quad$ A simple model of shipping supply}

For a shipowner to operate a vessel the net returns at optimum speed should cover variable costs. In shipping the net revenue per year $(R)$ is the freight income from a given voyage less the specific voyage costs, which mainly is port and bunkers costs. The net revenue is the objective value in the maximisation problem. Ship operators set optimum speed $\left(s^{*}\right)$ to maximise the net revenue $(R)$.

The net revenue per trip $(V)$ is the freight rate $(P)$ times tons carried $(t)$, less port charges $(h)$, loading and discharging cost $(c)$, bunkers cost when in harbour or waiting to enter the port $(b(w))$ and bunkers cost at sea $(b(s))$. Bunkers cost is the dominating voyage cost element besides cargo handling and port charges, since crew costs and capital costs accrue irrespective of whether the vessel is trading or waiting ${ }^{3}$. This gives the net revenue per trip:

(1) $V=P t-h-c t-b(w)-b(s)$

The number of round trips per year $(T)$ follows from distance $(\mathrm{m})$, vessel speed, days in port or waiting $(\mathrm{w})$ and at sea that is:

(2) $T=\frac{365}{w+m / 24 s}$

The net revenue per year $(R)$ is net revenue per trip times the number of trips. The number of round trips per year increases with speed and decreases with distance, days in port or waiting. Cargo volume $(t)$ and distance for the round trip are given by the trade. We assume that the ballast and cargo leg are similar, and assume that the vessel operates in the same route in the whole period:

(3) $R=\{P t-h-c t-b(w)-b(s)\} \cdot \frac{365}{w+m / 24 s}$

The total time in port or waiting $(w)$ is the time loading $(l)$ and discharging (d) cargo plus any waiting for port access $(v)$ :

\footnotetext{
${ }^{3}$ Canal dues are added when applicable.
} 
(4) $w=v+l+d$

From this model of transport supply we may find optimum speed by specifying the bunker consumption functions $b(w)$ and $b(s)$. See Norman and Wergeland (1981) and Strandenes (1986) for alternative specifications.

In this paper our focus is port charges, loading and discharging costs and vessel scheduling. Thus we will split cargo handling costs $(c)$ in loading $\left(c_{l}\right)$ and discharging $\left(c_{d}\right)$ costs:

$c t=c_{l} t+c_{d} t$

We will use the net revenue $(R)$ to illustrate effects of alternative pricing and scheduling.

\section{$3 \quad$ Existing port pricing structures}

\subsection{Traditional port pricing}

The traditional pricing structure is non-transparent with a set of tonnage charges, cargo charges and charges for specific services such as water, storage, pilots, etc. This implies that it is difficult for ship operators and charterers to compare costs of alternative ports or transport routes. Since pricing is not used to induce efficiency, the result is overall costlier transport.

There often is a preference for regional or coastal shipping in ports in this pricing structure. This favourism is based on the fact that port visits are often by vessels operating in short-sea trades. This is a large customer discount argument. The focus is on the fact that port costs make up a large share of the operating cost in short-sea shipping. From (2) we see that when distance $(m)$ is short the number of round trips $(T)$ is higher and so is the number of port visits. Whether a specific vessel or fleet of vessels are important to the port seems to be a more relevant argument for quantum discount.

Another characteristic in traditional pricing schemes is to favour exports. Charges often are set higher for imports than for exports. Favouring exports imply that loading is charged less than discharging that is from (5), $\left(\mathrm{c}_{\mathrm{d}}\right)>\left(\mathrm{c}_{1}\right)$ in international operations. A vessel operating between two ports will be just as well of if the discount on exports in the first or loading port $\left(c_{l}^{1}\right)$ is equal to the extra costs charged on imports at the second or destination port $\left(c_{d}^{2}\right)$ and vice versa. More important such price discrimination does not enhance efficiency in ship operations.

A third element found in traditional port pricing is differentiated cargo charges that mirror differences in cargo values that is "charging what the traffic will bear". Such a pricing scheme may increase port revenues given that the price differentiation does not induce cargo owners to reroute their vessels to alternative ports with a more favourable handling cost for their ship or cargo. If the shipowner can charge a higher freight rate $\left(P^{\mathrm{o}}\right)$ to cover the higher loading $c_{l}^{\circ}$ and discharging $c_{d}^{o} \quad$ costs, we have: 
(6) $P^{\mathrm{o}} t-P t=\left\{c_{l}^{\mathrm{o}} t+c_{d}^{\mathrm{o}} t\right\}-\left\{c_{l} t+c_{d} t\right\}$

From (3) we see that the voyage revenue will be the same irrespective of the value of the goods transported.

Irrespective of whether the port in setting higher charges for valuable cargoes gains higher revenue, such pricing structures do not influence the scheduling of vessels approaching the port. Vessels still have to wait according to the "first-come-first-served" scheduling principle.

\subsection{Cost-based pricing}

Compared to average cost pricing, prices based on long term marginal costs give more efficient signals on port capacity. In this case the marginal capacity is priced more correctly. When the marginal vessel is willing to pay a price above marginal port costs, this signals that the port capacity should be increased. Even though the capacity signals from marginal cost pricing are more relevant economically, marginal cost port pricing does not by itself induce a better scheduling of vessels since this pricing scheme disregards differences in waiting time for vessels. If cost-based pricing furthers investment in higher capacity waiting may be reduced. Expanding the capacity increases $(R)$ both by directly reducing waiting $(w)$ and bunker cost in port $b(w)$ and indirectly by increasing the number of round trips $(T)$ as is seen from (3).

Marginal cost pricing for port services will result in ports facing losses when infrastructure and/or cargo handling are characterised by economies of scale. Ports using marginal cost pricing thus have to be subsidized by the tax payers. Economies of scale elements in port costs follow from the fixed costs elements. Rudolf (1995) in his study set the capital costs for container cranes at 70 per cent of total costs. More generally, $80 \%$ of costs typically are independent of volume of cargo handled in container operations. Similarly for break-bulk operations, $60 \%$ of costs typically are independent of cargo volume (Bennathan and Walters, 1979, Jansson, 1984).

\section{$4 \quad$ Efficiency promoting port price structures}

The main criticism we have voiced against traditional infrastructure charging and costbased pricing of port service is that they do not induce ship efficiency. In a situation where short sea shipping competes stiffly with land based modes of transport and shipping tends to loose out irrespective of the safety and environmental problems caused by land transport, there are several reasons for using pricing schemes to increase the efficiency of the sea leg in the supply chain.

Changes in port pricing and vessels scheduling can raise that competitiveness of a supply chain that includes a sea leg. A pricing policy with such effects is consistent with political aim to increase the competitiveness of maritime transport to help reducing congestion problems. The EU commission has suggested "fair" pricing for infrastructure (European Commission, 1995) to obtain a more level playing field for the different transport modes. The policy aim is to reverse the steady ongoing shift towards road transport. Port and ship efficiency both are important in making such a policy successful. The transition from road transport is relevant for shorter distances in regional transport. At the same time port charges make up 40-60\% of overall transit costs in short-sea shipping, whereas port charges in deep-sea transport are only $5-10 \%$ of the costs (European 
Commission, 1997). Thus, increased efficiency that reduces waiting time (v) or time loading $(l)$ and unloading $(d)$, is important to reach the policy goal set by the Commission.

We will discuss three different pricing structures that may enhance ship efficiency: (1) congestion pricing, (2) priority pricing and (3) prices set by auction procedures.

\subsection{Congestion pricing}

Congestion pricing at the first sight may be thought to induce efficient use of limited port capacity and thereby avoid investment in extra capacity to handle systematic variations in the demand for its services. Ports that face daily, weekly or seasonal variations in demand, congestion pricing will induce shippers to adjust arrival times to reduce port costs. Hence, arrivals are spread more evenly in time and thereby the maximum port capacity may be kept at a lower level. This will reduce investment needs. Studies of Swedish ports in the 1980s estimated the optimal occupancy rate at 40 - $60 \%$ of full capacity (Jansson, 1984). This indicates a large potential for better occupancy rate if ship operators can be induced to spread vessel arrival times more.

The spreading out of arrivals by itself reduces time in port for vessels that used to arrive at peak hours. But congestion pricing has a further impact on ship efficiency. By increasing peak hour port charges, shippers with a higher willingness to pay for port capacity will be most prepared to pay the extra costs. This typically will be shippers that carry cargo with a higher need for punctuality, regularity or the shortest possible throughput time. The higher port charges reduce $(R)$. Shippers who cannot push the extra costs of peak hour charges onto the cargo owner by charging $\left(P^{\circ} t>P t\right)$ may opt for the more inconvenient off peak port slots to avoid paying the higher port charges. Hence, congestions pricing has the double effect of inducing a more spread out employment of port capacity and a better scheduling of vessels reflecting their relative cost of waiting for a cheaper port slot.

The second effect of higher ship efficiency may partly counteract the first effect that reduces the need for larger port capacity. When the opportunity cost of vessel or cargo time is high, most operators and cargo owners will be willing to pay to be handled at peak hours. If so, the great variations in exploitation of port capacity will remain. This situation still is better than under traditional port pricing schemes, however, since the port now will have a higher return to pay for the lower exploitation of its capacity outside peak hours. The effect of congestion pricing on ship efficiency will be limited though, when most vessels are able and willing to pay the peak hours charges. Then there will be limited or no sorting effect of congestion pricing on vessels according to their relative waiting costs.

\subsection{Priority pricing}

Priority pricing more directly focuses allocation of port slots to increase ship efficiency and thus the efficiency in the supply chain. Priority pricing may be constructed as a two part tariff, where ship operators pay an admission charge to get access to the port $(H)$, and a priority charge $f(\cdot)$ that guarantees the priority based on maximum turn around time for the vessels that is $\left(w^{\max }\right)$ and the throughput time for the cargo $\left(x^{\max }\right)$. Strandenes and Marlow (2000) suggested the following two part tariff profile:

$$
C=H+f\left(x^{\max }+w^{\max }\right) \text { where } H=\left(h+c_{l} t+c_{d} t\right)
$$


Port charges are listed in a menu of $i$ classes defined so that charges are higher that is $H_{i}>H_{j}$, when the guaranteed maximum time in port for the vessel and the cargo is shorter

that is $\left(x_{i}^{\max }+w_{i}^{\max }\right)<\left(x_{j}^{\max }+w_{j}^{\max }\right)$. The guarantee in addition may specify the maximum time allowed before the cargo is loaded onto land or rail transport and leaving the port. Priority pricing will be efficient when ship operators are sensitive to both port costs and time cost, as is the case in equation (3).

Priority pricing is a method by which the port differentiates its services. In this case the differentiation is related to the quality of the port service defined by the time cost for the vessel and the cargo. Thus, both punctuality and total time is relevant. Similar to other markets whose suppliers differentiate their prices according to differences in customers' willingness to pay, priority pricing may give higher average income to the port. The port authorities may gain by combining price differentiation and yield management. The gain may be a better exploitation of the total port capacity at a higher average price

Price differentiation in ports is not entirely new. Traditional port pricing sometimes include price differentiation. The criterion often used is to charge "what the traffic will bear" or differentiating by the value of the cargo as discussed above. Another usual criterion has been differentiating by the type of trade, that is short sea vs. deep sea or import vs. export as mentioned above. This traditional price differentiation may increase average revenue by "taxing" customers that are more dependent than others on using the port or those operators whose port costs make up a smaller part of the total voyage costs, that is customers' with inelastic demand for port services. Neither of these schemes for differentiation is designed primarily to influence ship efficiency. In contrast, differentiation based on quality as defined here, may better the position of shipping relative to land transport by increasing shipping's ability to compete on speed and punctuality. Introducing priority pricing thereby may support the policy aim to increase the market share of seaborne transport relative to land transport, and give favourable effects on road safety and environmental aspects.

So far we have argued that ports may gain by introducing price differentiation based on demand for quality (speed, punctuality) of port service and that those criteria are more relevant than the often used differentiation based on value of cargo. Quality based price differentiation enhances the competitiveness of seaborne transport relative to land based transport by focusing on time of delivery and total transport time in the supply chain with a seaborne leg. We now turn to the third alternative, focusing on port pricing and scheduling.

\subsection{Port slot auctions}

An auction approach for scheduling vessels to the available port capacity can be organised by letting ship operators bid for port slots. The port capacity is made available in time slots and an auction may be set up to distribute access to the port and the slots offered say during a specific week.

Ship operators do not necessarily prefer the earliest available slot in a slot auction. The port slot auction setup must comply with this characteristic. In traditional auctions scheduling demand, the first slot is best. Since vessel operators plan their schedule, they may prefer to have the second or later slot. The suggested port slot auction must therefore allow for preferences for specific slots and not necessarily the earliest one.

It furthermore is necessary to set up an auction procedure where time per slot differs. Ships differ in size and cargoes require different cargo handling procedures. Therefore 
ships will require different service times. For the port slot auction to function the different duration of the allocated slots must be taken into account.

For a port slot auction to be favourable for the port, the prices for the slots set by the auction must be non-negative. If not the port would need high(er) subsidies. With negative prices there are few reasons to induce vessels to use the slots, except if this is part of a policy to favour seaborne transport to avoid land transport.

The port slot auction scheme also needs to allow for a forward market in slots. This is essential to cater for operators operating in fixed routes with pre set departures and arrivals such as container lines. In the current procedure for port slot allocation, large liner operators typically use dedicated terminals or long term contracts to secure loading and unloading at preset times. As we argued above, this gives a low exploitation of part of the port capacity when the line does not fully use the capacity of the terminal. Ship operators offering contracts of affreigthment (COAs) ${ }^{4}$ may also need to buy slots forward. They have agreed to supply transport of fixed cargo volumes over a period for example a year. In addition to the total volume per period they also agree to supply the cargo within narrow time windows. They thus need to secure ports slots to be able to offer the service with a minimum of trustworthiness. A forward slot market may be valued also by operators in the spot charter markets ${ }^{5}$. In several spot markets fixtures are settled weeks before the vessels are expected to pick up their cargo. In such instances the operator may enter the forward market to secure port access to fulfil the pick up and delivery dates of the spot contract.

Vessels' itineraries change on short notice. Weather conditions may cause delays. Sale of the cargo or changes in cargo owners' plans may result in a rerouting of the cargo to another port after the slot at the first destination has been bought in the auction. Therefore the auctions should allow for a sell back of slots that is no longer needed.

For spot and forward port slot auctions to be efficient it is necessary that buyers of slots in the forward auction have incentives to bring the slot back to the spot auction. Strandenes and Wolfstetter (2003) formulate an auction procedure that gives such incentives and fulfils the characteristics described above.

There are several gains from forward markets in slots. Forward sales make the port attractive to ship owners by admitting longer term planning. The integration of seaborne transport into a supply chain similarly increases the importance of planning.

Re-sale of forward contracts reduces the number of unused slots and increased the capacity utilisation of the port. The result may be to postpone or eliminate the need for higher port capacity and the need for larger land areas.

As sellers of forward slots ports might see forward sales a hedge against variations in future trade and against the cost of excess port capacity in the future. This is not the main gain from slot auctions, however, since the prices obtained in the future auctions are not known. Prices may be lower than expected by the port, since prices will vary with operator's willingness to pay in the future. Thus, the hedge against unused port capacity is not an efficient hedge against varying revenue from port slot sales.

\footnotetext{
${ }^{4}$ Contract of Affreightment - Owners agree to accept a cost per revenue tonne for cargo carried on a specific number of voyages. (http://www.shipbrokering.com/Shippingterm.html) Thus the shipowner will agree to carry the cargo for an agreed price per tonne and to deliver a certain tonnage per month, or per voyage. The shipowner is free to choose what ship to use in the operation.

${ }^{5}$ In the spot charter market, shippers and shipowners agree on a single trip for a specific vessel with a given cargo.
} 
The port slot auction procedure suggested by Strandenes and Wolfstetter (2003) has limitations that make it less convenient for some shipping markets. Firstly, the suggested procedure does not handle interdependencies between port calls for loading and unloading. For many shipping operators such interdependence is not essential. A typical trip takes more weeks and in contrast to the airline business, it is not imperative to know where to land before leaving the loading port.

The problem is more relevant to feeder operations. They may require that the interdependence between loading of the deep sea carrier and loading of the feeder carriers are coordinated. Such interdependence between the slots is not possible for the described procedure, and this procedure therefore disregards that operators may be willing to pay more for adjacent slots

The main gains from slot auctions can be summarized: (1) reduce allocation inefficiencies seen in first-come -first -serve allocation rule, (2) allow for planning via forward slot sales and allow for re-sale of slots bought forward, (3) assure non-negative prices for slots, (4) are deficit free, and (5) the port gets the scarcity rent of port capacity and gets right incentives to invest.

\section{Conclusions}

We have argued that port pricing influences ship as well as port efficiency. Several suggestions have been put forward to switch from traditional infrastructure pricing schemes still in use by most ports, such as cost-based or cost-recovery pricing. Congestion pricing has also been suggested. These pricing schemes may enhance port efficiency if properly employed. They will not directly raise ships efficiency, though.

For operators who cannot operate under the inefficient but common "first-come-firstserve" allocation rule, ports can offer long-term contracts for port capacity by allowing operators to invest in dedicated terminals. Such pre-booking may increase vessel efficiency, but often reduce the exploitation of total port capacity if the ship operators do not need the full capacity of the terminal, neither for their own operations nor to let out excess capacity to other shipping lines.

We have discussed some alternative price structures that handle ship efficiency more directly:

- $\quad$ Priority pricing exemplified as two part tariffs where an access fee is charged to cover the fixed cost of the port and a quality fee is used to let ship operators buy guarantees for efficient handling. The gain is a maximum turn around time for the vessel and throughput time for the cargo.

- Slot auctions to increase ship efficiency by scheduling vessels according to their willingness to pay for a specific port slot that fits the itinerary of the ship and reduces the waiting time for vessel and cargo.

The price paid to the port using these two pricing and scheduling schemes furthermore gives the port incentives to adjust its capacity to the demand for port slots and cargo handling. 


\section{$6 \quad$ References}

Bennathan, E. and A. A. Walters (1979) Port Pricing and Investment Policy for Developing Countries. Oxford University Press: Oxford.

Cullinane, Kevin (2002) "The Productivity and Efficiency of Ports and Terminals: Methods and Applications," in Grammenos, Costas Th. (ed.) The Handbook of Maritime Economics and Business. LLP: London.

European Commission (1995) Towards Fair and Efficient Pricing in Transport: Policy Options for Internalising the External Costs of Transport in the European Union, COM (95) 69, Brussels. http://europa.eu.int/comm/off/green/index_en.htm\#1995

European Commission (1997) Green paper on seaports and maritime infrastructure, COM (97) 678 Final, European Commission $_{2}$ Brussels. http://europa.eu.int/comm/off/green/index en.htm\#1997

Jansson, J. O. (1984) Transport System Optimization and Pricing. Wiley: Chichester.

Norman, V. D. and T. Wergeland (1981) Nortank - A Simulation Model of the Freight Market for Large Tankers. Center for Applied Research, Norwegian School of Economics and Business Administration: Bergen.

Rudolf, C. D. (1995) "A cost Comparison of Modern Container Cranes," Proceedings de la Conferencia: Ports'95, American Society of Civil Engineers.

Shipbroker Shipping Abbreviations. http://www.shipbrokering.com/Shippingterm.html 20040521

Strandenes, S. P. (1986) Norship - A Simulation Model for Bulk Shipping Markets. Center for Applied Research, Norwegian School of Economics and Business Administration: Bergen.

Strandenes, S. P. and P. B. Marlow (2000) "Port Pricing and Competitiveness in Short Sea Shipping," International Journal of Transport Economics, 27: 315 - 334.

Strandenes, S. P. and E. Wolfstetter (2003) "Efficient (Re-) Scheduling: An Auction Approach," Discussion paper, Department of Economics, Humboldt-University at Berlin, October. http://www.wiwi.hu-berlin.de/wt1/papers/index.html 